\title{
Comment on Cassell and Clapperton: A decreasing trend in fall-related hip fracture incidence in Victoria, Australia
}

\author{
J. A. Stevens $\cdot$ R. A. Rudd
}

Received: 24 July 2013 / Accepted: 15 November 2013 / Published online: 30 November 2013

(C) International Osteoporosis Foundation and National Osteoporosis Foundation 2013

\section{Dear Editor,}

We read with interest the recent article by Cassell and Clapperton describing the decreasing trend in fall-related hip fracture rates among people aged 65 and older in Victoria, Australia from 1998/99 to 2008/09 [1]. Over this time period, hip fracture rates decreased by $25 \%$ among men and $23 \%$ among women. Similar trends have been seen in other countries. We previously reported trends in hip fracture hospitalization rates among people aged 65 and older in the USA from 1990 to 2010 [2, 3]. Looking at the time period from 1998 to 2008, US rates declined by $22 \%$ for men and $28 \%$ for women - very similar to Cassell and Clapperton's results.

Although the overall findings of this Australian study and our US studies are comparable, there are also some important differences. Cassell and Clapperton examined trends in hip fracture rates for men and women aged 65 and older separately and for both sexes combined by 5 -year age groups, while we looked at trends in rates by 10 -year age groups for men and women aged 65 and older separately. We found that most rates for men and women decreased significantly from 1996 to 2010 , with the sharpest decline occurring among women aged 85 and older (annual percent change $=-3.3 ; 95 \%$ confidence interval $=-4.2$ to -2.3 ). However, rates did not decrease significantly among men aged 65 to 74 . Over the next two to three decades, these trends are likely to result in fewer hip fractures than Cassell and Clapperton's study might suggest. Underlying causes for these trends are unclear, but it does not appear to be a result of osteoporosis treatment with bisphosphonates, which is not widely used and often discontinued due to unpleasant side effects $[4,5]$. Other

J. A. Stevens $(\bowtie) \cdot$ R. A. Rudd

4770 Buford Highway NE, Mailstop F-62, Atlanta, GA 30341, USA

e-mail: jas2@cdc.gov

R. A. Rudd

e-mail: Rvr2@cdc.gov possible explanations include a healthy cohort effect, improved intake of calcium and vitamin $\mathrm{D}$, and increased body weight. More research is needed to clarify the mechanisms underlying these trends.

Populations are aging worldwide. By 2030, the segment of the US population aged 65 and older will increase over $80 \%$ [6]. If the current trends in hip fracture rates continue, the decreasing rates among women, especially among the oldest women, will help offset the number of hip fractures expected due to the aging population. However, these trends also will affect the distribution of hip fractures. Whereas men sustained $28 \%$ of hip fractures in 2010 , this proportion may rise to $38 \%$ by 2030 [3]. To reduce the number of hip fractures now and in the future, it is essential that we implement effective fall prevention strategies, especially among older men who may sustain a greater proportion of future hip fractures.

\section{References}

1. Cassell E, Clapperton A (2013) A decreasing trend in fall-related hip fracture incidence in Victoria, Australia. Osteoporos Int 24:99-109. doi:10.1007/s00198-012-1937-6

2. Stevens JA, Rudd RA (2010) Declining hip fracture rates in the United States. Age Aging 39(4):500-509

3. Stevens JA, Rudd RA (2013) The impact of decreasing U.S. hip fracture rates on future hip fracture estimates. Osteoporos Int 24: 2725-2728. doi:10.1007/s00198-013-2375-9

4. Siris ES, Harris ST, Rose CJ et al (2006) Adherence to bisphosphonate therapy and fracture rates in osteoporotic women: relationship to vertebral and nonvertebral fractures from 2 US claims databases. Mayo Clin Proc 81(8):1013-1022

5. Tosteson ANA, Grove MR, Hammond CS et al (2003) Early discontinuation of treatment for osteoporosis. Am J Med 115:209-216

6. U.S. Census. Available at http://www.census.gov/population/ projections/data/national/2012/summarytables.html. Accessed 28 March 2013 